\title{
Correlation between Anthropometric Measures, Blood Glucose, and Cholesterol Levels in College-Aged Hispanic Males
}

\author{
DANNY DOMINGUEZ, MARGARITA GONZALEZ, JUAN PAREDES, RUBEN \\ CHIPULI, MURAT KARABULUT, and ULKU KARABULUT-
}

Health and Human Performance Laboratory; Health and Human Performance; University of Texas at Rio Grande Valley; Brownsville, TX

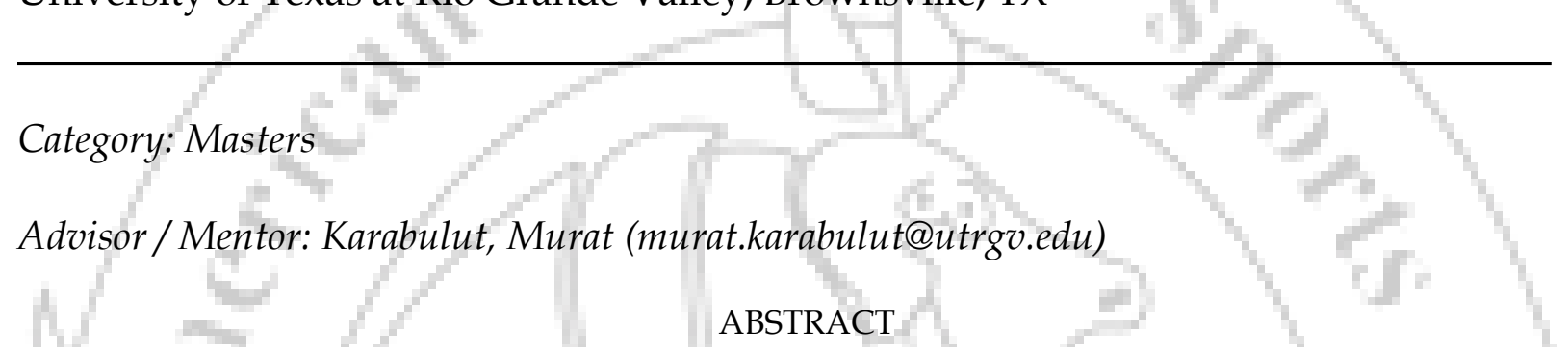

PURPOSE: To investigate the relationship between anthropometric measures, blood pressure (BP), total cholesterol (TC), fasting blood glucose (FBG), and high density lipoprotein cholesterol (HDL) among Hispanic college-aged males 18 to 30 in the Lower Rio Grande Valley. METHODS: Thirty-five male subjects (age $=23.2 \pm 2.8$ ) read and signed the informed consent prior to participation in this study. Subjects had their height, weight, and three circumference measurements taken [waist at umbilicus (WU), waist at smallest point (WSP), and hip at widest point (HWP)] and their body mass index (BMI) calculated. A fasting blood sample was taken to analyze TC, HDL, and FBG; in addition, TC:HDL ratio and non-HDL were calculated. Percent body fat $(\mathrm{BF})$ was also measured using air displacement plethysmography. RESULTS: Age was found to be significantly correlated with weight $(\mathrm{r}=0.491, \mathrm{p}<0.01), \mathrm{BF}(\mathrm{r}=0.575, \mathrm{p}<$ $0.01)$, BMI $(r=0.539, p<0.01)$, diastolic (DBP) $(r=0.427, p<0.01)$, WSP $(r=0.596, p<0.01)$, WU $(r=0.638, p<$ $0.01)$, and HWP $(r=0.485, p<0.01)$, and non-HDL $(r=0.405, p<0.02)$. BF and BMI were significantly correlated with HDL $(r=-0.370, p<0.03 ; r=-0.384, p<0.03)$ and correlated with TC:HDL ratio $(r=0.466$, $\mathrm{p}<0.01 ; \mathrm{r}=0.441, \mathrm{p}<0.01)$. WSP, WU, and HWP were significantly correlated with TC:HDL ratio $(\mathrm{r}=0.429$, $\mathrm{p}<0.01 ; \mathrm{r}=0.449, \mathrm{p}<0.01 ; \mathrm{r}=0.372, \mathrm{p}<0.03$ ), while only the WU and HWP circumference measurements were significantly correlated with HDL cholesterol $(r=-0.369, p<0.03 ; r=-0.428, p<0.01)$. CONCLUSIONS: The results indicated age had notable correlations across most measures, even within this small 12-year range, which may be due to a decrease in physical activity throughout the college career. The data indicated higher BMI and BF were similarly correlated with lower HDL blood concentration and an increased TC:HDL ratio. This suggests that BMI is still a strong predictor of cholesterol level and can be relied upon when body composition analyzation is not available. Our results also indicated that location of the waist measurements is important and WU may be preferred site for determining negative risk factor regarding cholesterol in college-aged Hispanic males.

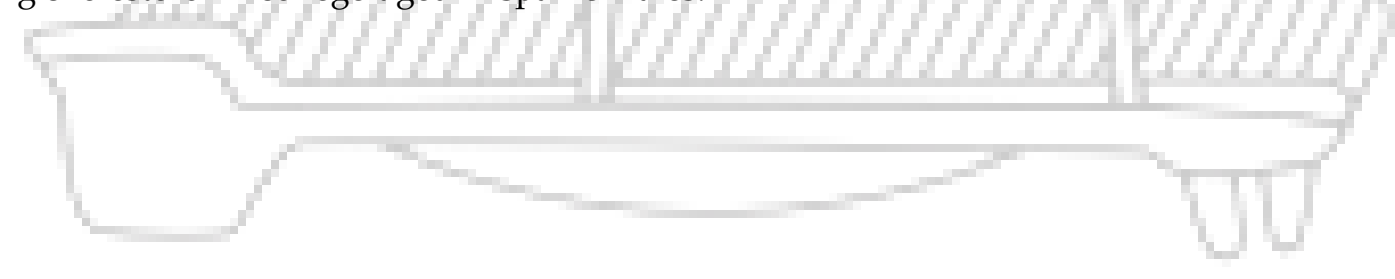

